\title{
AUGMENTATION OF TURBULENT FLOW HEAT TRANSFER IN A HORIZONTAL TUBE WITH VARYING WIDTH TWISTED TAPE INSERTS
}

\author{
S. Naga Sarada, A.V. Sita Rama Raju, K. Kalyani Radha and L. Syam Sunder \\ Faculty of Mechanical Engineering, JNTUH College of Engineering, Kukatpally, \\ Hyderabad-500085, Andhra Pradesh, India; Phone: +91 9440517729. \\ E-mail:kalyaniradha@gmail.com
}

\begin{abstract}
The present work shows the results obtained from experimental investigations of the augmentation of turbulent flow heat transfer in a horizontal tube by means of varying width twisted tape inserts, with air as the working fluid. In order to reduce excessive pressure drops associated with full-width twisted tape inserts, with a lower corresponding reduction in heat transfer coefficients, reduced-width twisted tapes of widths ranging from $10 \mathrm{~mm}$ to $22 \mathrm{~mm}$ are used, which are lower than the internal diameter of the tube of $27.5 \mathrm{~mm}$. Experiments were carried out for plain tubes with/without twisted tape inserts at a constant wall heat flux and different mass flow rates. The twisted tapes are of three different twist ratios (3, 4 and 5), each with five different widths (26 (full-width), 22, 18, 14 and $10 \mathrm{~mm}$ ). The Reynolds number varied from 6000 to 13500 . Both the heat transfer coefficient and pressure drop are calculated, and the results are compared with those of a plain tube. It is observed that with the inclusion of twisted tape inserts there is a significant increase in the heat transfer coefficients. Correlations are developed for friction factors and Nusselt numbers for a fully-developed turbulent swirl flow, which are applicable to full-width as well as reduced-width twisted tapes, using a modified twist ratio as the pitch to width ratio of the tape.
\end{abstract}

Keywords: Enhancement; heat transfer; varying width; twisted tape inserts; turbulent; swirling; pressure drop.

\section{INTRODUCTION}

Among many techniques (both passive and active) investigated for the augmentation of heat transfer rates inside circular tubes, a wide range of inserts have been utilized, particularly when turbulent flow is considered. The inserts studied included coil wire inserts, brush inserts, mesh inserts, strip inserts, twisted tape inserts, etc. Augmentation of convective heat transfer in the internal flows with tape inserts in tubes is a wellknown technique employed in industrial practice. Hsieh and Huang (2000) conducted experimental studies on the heat transfer and pressure drop of laminar flow in horizontal tubes with/without longitudinal inserts. They reported an enhancement in heat transfer compared to a conventional bare tube at the same Reynolds number of a factor of 16 at $\operatorname{Re}<=4000$, while the friction factor only rose by 4.5 . A new method was proposed by Sarma et al. (2003) for the prediction of heat transfer coefficients with twisted tape inserts in a tube in which the wall shear and the temperature gradients were modified through friction coefficient correlation, leading to heat transfer augmentation from the tube wall. The laminar flow regime with tape could be successfully treated for a wide range of parameters, with Prandtl numbers varying from 3 to 400 and pitch ratios 
varying from 2.5 to 10 . Correlations were developed, yielding close agreement with the correlations of other investigators. Experimental studies were conducted on the heat transfer and flow characteristics for a turbulent flow of air in a horizontal circular tube with a strip type insert (longitudinal and crossed strip inserts). They reported that the friction factor rise due to the inclusion of inserts was typically between 1.1 and 1.5, from low $\operatorname{Re}(=6500)$ to high $\operatorname{Re}(=19500)$, with respect to the bare tube (Hsieh et al., 2003). Naphon (2006) conducted experimental investigations on the heat transfer characteristics and pressure drop in horizontal double pipes with twisted tape inserts, and the results obtained from the tube with twisted inserts are compared with those without twisted tape. Heat transfer, friction factor and enhancement efficiency characteristics in a circular tube fitted with conical ring turbulators and a twisted-tape swirl generator were investigated experimentally (Promvonge and Eiamsa-ard, 2007). Air was used as the test fluid. The Reynolds number varied from 6000 to 26000, and the average heat transfer rates from using both the conical-ring and twisted tape for twist ratios of 3.75 and 7.5 respectively are found to be $367 \%$ and $350 \%$ over the plain tube.

Monheit (1987) conducted a comparative study of the thermal performance of ordinary full-width full-length twisted tapes, using tapes with modified surface configurations. The modified tape was either a tape with circular holes on its surface or one with slits along its edges. For laminar flow heat transfer to the lubricating oil (Re: 560-3500, Pr: 5150-450) such modifications offered no advantage over ordinary twisted tape. Dasmahapatra and Raja Rao (1991) studied the augmentation of heat transfer to viscous non-Newtonian fluids in laminar flow using full-width interrupted twisted tapes under a uniform wall temperature condition. They found that regularlyspaced tapes give 15-35\% lower friction factors and only a 10-20\% reduction in Nusselt numbers compared to full-width full-length twisted tapes, for a range of twist ratios $(y=2.4-5.04)$ and space ratios $(S=2.2-4.0)$. Al-Fahed et al. (1998) and Bergles et al. (1974) investigated the effect of tube-tape clearance on heat transfer under fullydeveloped turbulent (Al-Fahed and Chakroun, 1996) and laminar conditions. They demonstrated that as the tube-tape clearance decreases, the heat transfer enhancement increases. However, they did not present correlations for predicting the heat transfer coefficients and friction factors. They recommended the use of loose-fit ( $w=10.8 \mathrm{~mm}$ ) tape in low twist ratios $(y=3.6,5.4)$ and high pressure drop situations, since it is easier to install and remove. However, the ease of installation should not be the criterion to recommend a particular geometry, and the selection of the optimum geometry should be based on the hydrothermal performance of the system. Performance evaluation criteria for enhanced heat transfer surfaces are reviewed (Bergles et al., 1974). Experiments were conducted on compound heat transfer enhancement in a tube fitted with serrated twisted tape in the Reynolds number range of 5000 to 25000 (Chang et al., 2007). Heat transfer augmentation due to the insertion of serrated twisted tape was observed to be in the range of 250 to $480 \%$ of the plain tube. Experiments were carried out with smoothwalled and serrated twisted tapes with twist ratios of 1.56, 1.88 and 2.81. The ratios of Nusselt number with insert to that without an insert was found to be 3.5, 2.99 and 2.12 for the smooth-walled tube and 4.8, 4.21 and 3.06 for serration roughened tubes, for twist ratios of 1.56, 1.88 and 2.81 , respectively. The heat transfer and pressure drop characteristics of laminar flow in rectangular and square plain ducts and ducts with twisted-tape inserts were experimentally investigated by Saha and Mallick (2005). The heat transfer test section was under uniform wall heat flux conditions. Local pressure drop measurements as well as the axial variation in duct wall temperature indicated that the flow was periodically fully-developed after some distance from the upstream end in 
the case of regularly-spaced twisted-tape elements. They reported that the development length depends on the values of twist ratio $(y)$, space ratio $(s)$, Reynolds number $(R e)$ and Prandtl number $(P r)$. The higher the $R e, y, s$ and $\operatorname{Pr}$ the higher the development length. The distance after which the straight flow became established depended on the twist ratio and the length of the twisted-tape. Friction factor and Nusselt number correlations were developed for the cases mentioned above. They reported that regularly-spaced twisted-tape elements performed significantly better than full-length twisted tapes.

Experimental studies for tubes fitted with left-right twisted tape inserts of various twist ratios were examined to enhance the convective heat transfer rates of a thermosyphon solar water heater system (Jaisankar et al., 2008). The swirl flow was induced by left-right twisted tape in clockwise and counterclockwise directions inside the riser tube, which enhanced the heat transfer. The various parameters such as Nusselt number, friction factor and thermal efficiency were studied. Empirical correlations developed for the Nusselt number and friction factor for various left-right twist ratios (3, 4,5 and 6) were found to fit the experimental data within $\pm 6.36 \%$ and $\pm 5.69 \%$ respectively. The results showed that the thermal performance of a tube fitted with a left-right twisted tape collector was better than the plain tube collector. The increased thermal performance of the twisted tape collector was due to the introduction of swirl flow. Experimental investigations were carried out on the heat transfer enhancement and pressure drop characteristics in the presence of twisted tape inserts, during flow boiling of R-134a, inside a horizontal evaporator (Akhavan-Behabadi et al., 2009). The testevaporator with $7.5 \mathrm{~mm}$ internal diameter was an electrically-heated $1260 \mathrm{~mm}$ long copper tube. The experiments were performed for plain flow, and on four tubes with twisted tapes of 6, 9, 12 and 15 twist ratios and four refrigerant mass velocities of 54, 85,114 and $136 \mathrm{~kg} / \mathrm{s} \mathrm{m}^{2}$ for each tape. They found that the twisted tape inserts enhanced the heat transfer coefficient with a relatively higher-pressure drop penalty, in comparison to that for plain flow.

Patil (2000) studied the frictional and heat transfer characteristics of the laminar swirl flow of pseudo plastic type power law fluid in a circular tube using varying width twisted tapes under uniform wall temperature conditions. The objective of using reduced-width twisted tapes is to reduce the pressure drops associated with full-width twisted tapes, without seriously impairing heat transfer augmentation rates and to achieve material savings. Reduced-width twisted tape inserts gave 18-56\% lower isothermal friction factors than the full-width tapes. The present investigation is aimed at studying the frictional and heat transfer characteristics in the turbulent region using varying width twisted tape inserts under a constant wall heat flux. The objective of using varying (reduced) width twisted tapes is to reduce the pressure drops associated with full-width twisted tapes, without seriously impairing the heat transfer augmentation rates and to achieve material savings.

\section{EXPERIMENTAL SET-UP}

The apparatus consists of a blower unit fitted with a pipe, which is connected to the test section located in a horizontal orientation. A nichrome bend heater encloses the test section to a length of a $40 \mathrm{~cm}$. Four thermocouples, $T_{2}, T_{3}, T_{4}$ and $T_{5}$, at a distance of 5 $\mathrm{cm}, 15 \mathrm{~cm}, 25 \mathrm{~cm}$ and $35 \mathrm{~cm}$ from the origin of the heating zone are embedded along the walls of the tube, and two thermocouples are placed in the air stream, one at the entrance $\left(T_{1}\right)$ and the other at the exit $\left(T_{6}\right)$ of the test section, to measure the temperature 
of flowing air, as shown in Figure 1. The pipe system consists of a valve, which controls the airflow rate and an orifice meter to determine the volume flow rate of the air through the system. The diameter of the orifice is $14 \mathrm{~mm}$, with a coefficient of discharge of 0.64 .

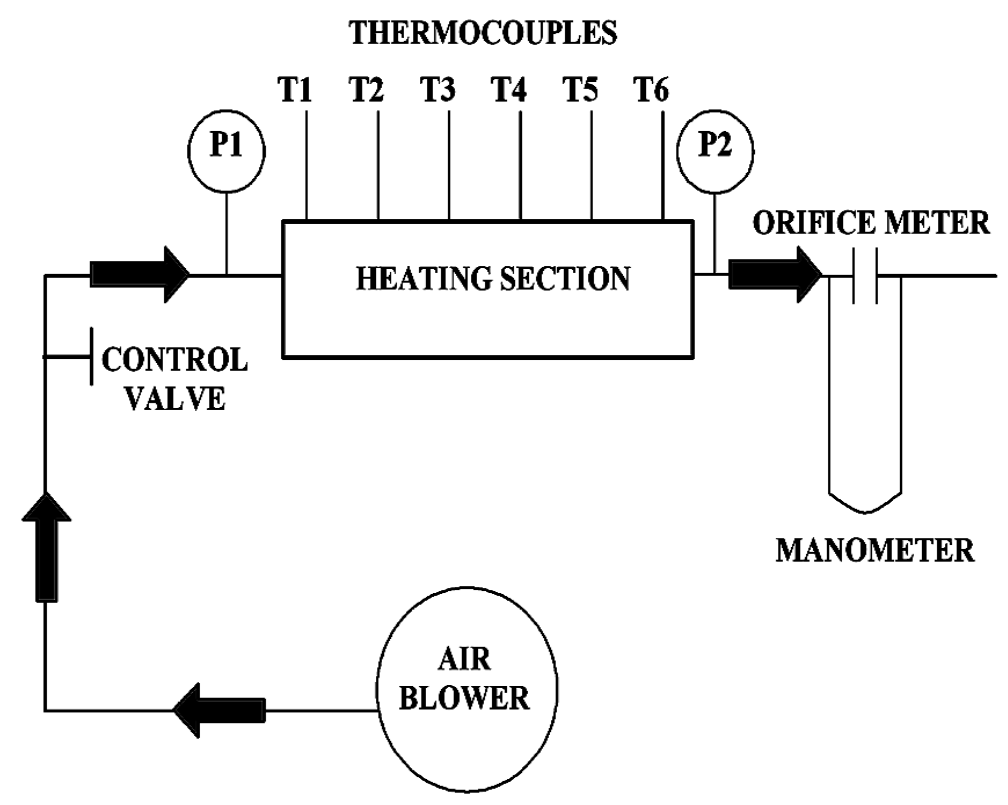

Figure 1. Experimental set up

Two calibrated pressure gauges ( $P_{1}$ and $P_{2}$ range: $0-1000 \mathrm{~mm}$ of water column) are provided to measure the pressure drops across the test section. Input to the heater is given through a dimmer stat. The inner tube of the heating part, which is the test tube with an inside diameter of $27.5 \mathrm{~mm}$, is made of $3.2 \mathrm{~mm}$ thick copper plate. The display unit consists of a voltmeter, ammeter and temperature indicator. The circuit was designed for a load voltage of $0-220 \mathrm{~V}$, with a maximum current of $10 \mathrm{~A}$. The difference in the levels of the manometer fluid represents the variations in the flow rate of air. The velocity of airflow in the tube is measured with the help of an orifice plate and the on-board water manometer.

\section{Experimental Work}

The layout of the tubes containing full-width and reduced-width twisted tapes is shown in Figure 1. The tapes consist of uniformly long aluminum strips of desired width, which have been twisted about the longitudinal axis. Twisted tapes of five different widths $(26,22,18,14$ and $10 \mathrm{~mm})$ were fabricated for each of the three different pitches, 82.5, 110 and $137.5 \mathrm{~mm}$, as shown in Figure 2. For the case of reduced-width tapes, the gap between the tube wall and the tape was maintained as constant throughout the tube length. The tapes of full-width $(26 \mathrm{~mm})$ were inserted as is into a $27.5 \mathrm{~mm}$ diameter tube, to give a sliding fit. 


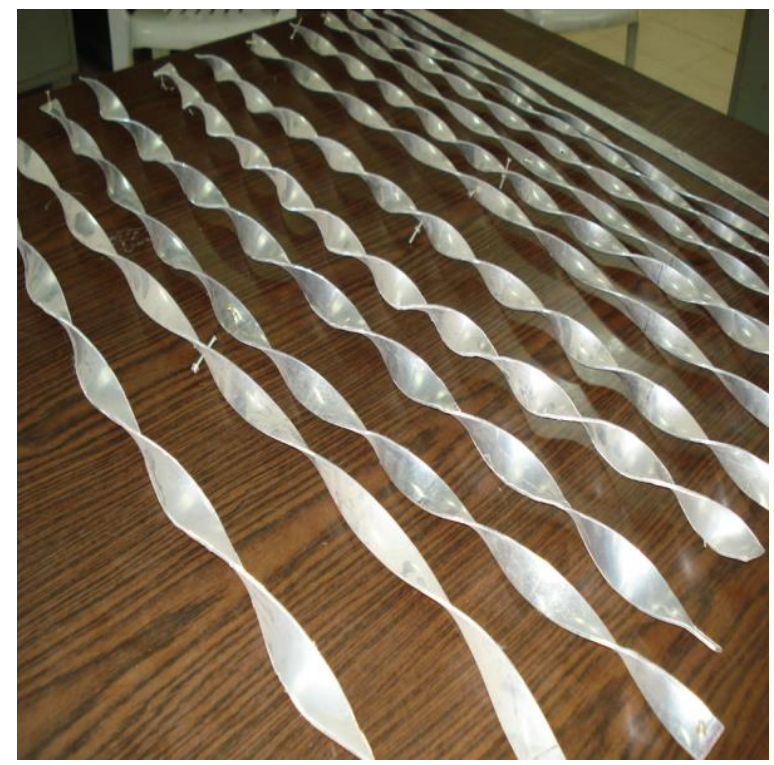

Figure 2. Photograph of twisted tape inserts

\section{Procedural Details}

Supply is provided to the blower motor and the valve is opened slightly. A heat input of $40 \mathrm{~W}$ is provided to the nichrome heating wire wound around the test section by adjusting the dimmer stat. Thermocouples 2 to 5 are fixed onto the surface and thermocouples 1 to 6 are fixed inside the pipe. Thermocouples used for experimentation are J-type with an accuracy $\pm 0.2 \%$. The readings of the thermocouples are observed every 5 minutes until they show constant values. Under steady state conditions, the readings of all six thermocouples are recorded. The experiment is repeated for different openings of the valve, thus varying the airflow rate. The fluid properties were calculated as the average between the inlet and the outlet bulk temperature. It took 110 minutes to reach steady state conditions. The experiment was carried out at constant heat flux conditions and a constant heat input of $40 \mathrm{~W}$ at different mass flow rates.

Initially the experiment is carried out without any insert (plain tube experiment). The working fluid air flows through the pipe section with the least resistance. The experiment is carried out in a similar fashion with straight tape inserts, and with twisted tape inserts with twist ratios (pitch/diameter) of 3, 4 and 5 for widths of 26, 22, 18, 14 and $10 \mathrm{~mm}$. The inserts are made of aluminum. The mass flow rates considered for a constant heat input of $40 \mathrm{~W}$ in terms of water level difference in the U-Tube water manometer are 2, 3, 4 and 5 inches (air mass flow rate varying from 0.0033 to 0.0055 $\mathrm{kg} / \mathrm{sec}$ ). The different types of insert used are shown in Table 1. Each insert in Table 1 is experimentally investigated for three different mass flow rates of air. Each insert is taken and axially inserted into the test section. Care is taken that the strip does not scratch the inner wall of the pipe and become deformed. The presence of the insert in the pipe causes a resistance to the flow and increases the turbulence. In the case of reduced-width tapes, the gap between the tube wall and the tape was constantly maintained throughout the tube length by brazing metal pins to the edges of the tape. 
Table 1. Different types of insert used

\begin{tabular}{clc}
\hline S. No. & Twist ratio (T.R) & Width of tape insert $(\mathbf{m m})$ \\
1 & 3,4 and 5 & $26,22,18,14$ and 10 \\
2 & Straight tape & $26,22,18,14$ and 10 \\
3 & Plain tube & ------------- \\
\hline
\end{tabular}

\section{EXPERIMENTAL UNCERTAINTY}

Experiments were initially conducted for a plain tube without inserts for different mass flow rates of air. The Nusselt number obtained from the experimental work is compared with the value obtained using the Dittus-Boelter equation (theoretical) (Figure 3). It is seen that the experimental results are in good agreement with the aforementioned studies, and $\mathrm{Nu}$ (experimental) is less than $\mathrm{Nu}$ (Dittus-Boelter). The actual heat carried away by air passing through the test section is the combination of convective and radiative heat transfers. As the heat transferred by convection alone is considered when performing numerical calculations (Eq. 8), it can be expected that $\mathrm{Nu}$ (experimental) is less than $\mathrm{Nu}$ (Dittus-Boelter).The experimental uncertainty is found to be $7.6 \%$ for the Nusselt number. The friction factor was observed to decrease with an increase in Reynolds number for the plain tube.

\section{Plain tube}

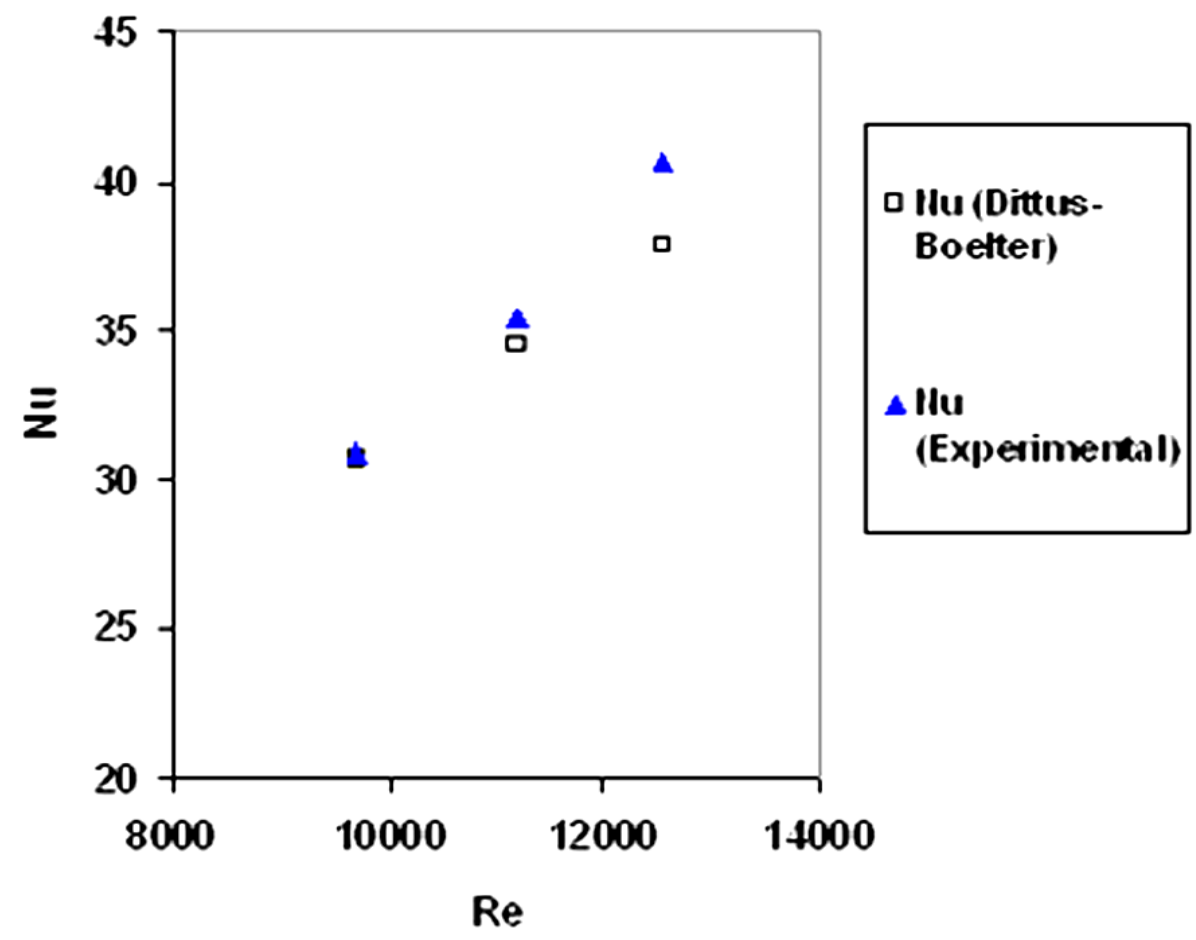

Figure 3. Comparison of Nusselt number for plain tube 


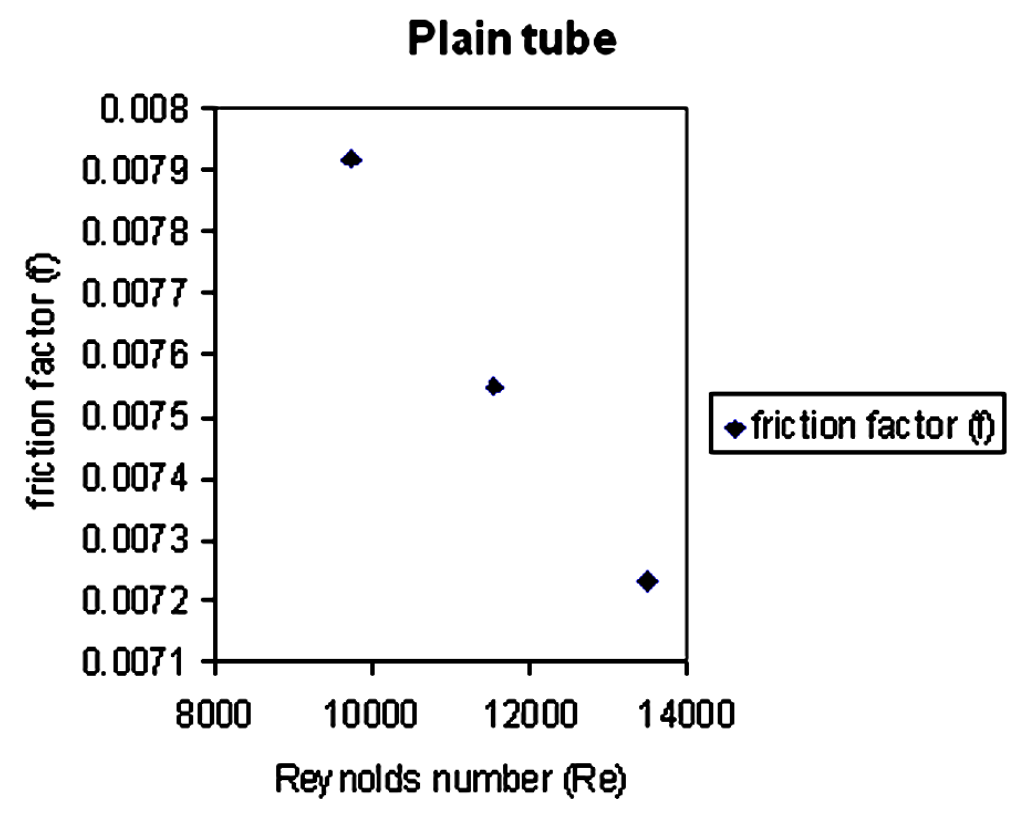

Figure 4. Variation in friction factor with Reynolds number for plain tube

\section{HEAT TRANSFER CALCULATIONS}

$$
\begin{gathered}
T_{\mathrm{s}}=\left(T_{2}+T_{3}+T_{4}+T_{5}\right) / 4 \\
T_{b}=\left(T_{1}+T_{6}\right) / 2
\end{gathered}
$$

Equivalent height of air column, $h_{a i r}=\left(\rho_{w} * h_{w}\right) / \rho_{a}$

Discharge of air, $d=C_{d} A_{p} A_{o} \sqrt{ }\left(2 g h_{\text {air }}\right) \sqrt{ }\left(A_{p}^{2}-A_{o}^{2}\right)$

Velocity of air flow, $U=d / A p$

Reynolds number, $R e=U D / v$

(To calculate $R e$ while using tape inserts, $D_{h}$ is used instead of $D$ )

$N u_{\text {the }}=0.023 \operatorname{Re}^{0.8} \operatorname{Pr}^{0.4}$

$Q=m^{*} C_{p} *\left(T_{1}-T_{6}\right)$

$Q r=\sigma^{*} A^{*} \varepsilon_{C}^{*}\left(T_{s}^{4}-T_{b}^{4}\right)$

$h=\left(Q-Q_{r}\right) /\left(A\left(T_{s}-T_{b}\right)\right)$

$\mathrm{Nu}=h \mathrm{D} / \mathrm{K}$

(To calculate $\mathrm{Nu}$ while using tape inserts, $D_{h}$ is used instead of $D$ )

$f_{\text {the }}=0.25\left(1.82 * \log _{10} R e_{D}-1.64\right)^{-2}$

$f=\Delta P /\left((L / D)\left(\rho_{a} U^{2} / 2\right)\right)$

$\eta=\left(N u_{i} / N u\right) /\left(f_{i} / f\right)^{0.333}$ 


\section{RESULTS AND DISCUSSION}

\section{Heat Transfer and Overall Enhancement Characteristics}

The variation in Nusselt number with Reynolds number for straight tape inserts is shown in Figure 5. The highest Nusselt number was obtained for the full-width straight tape. The mean heat transfer gain for the straight tape inserts varied from 4 to $24 \%$ compared to the plain tube. This is due to the strong turbulence intensity generated by the tape inserts, leading to the rapid mixing of the flow causing heat transfer enhancement.

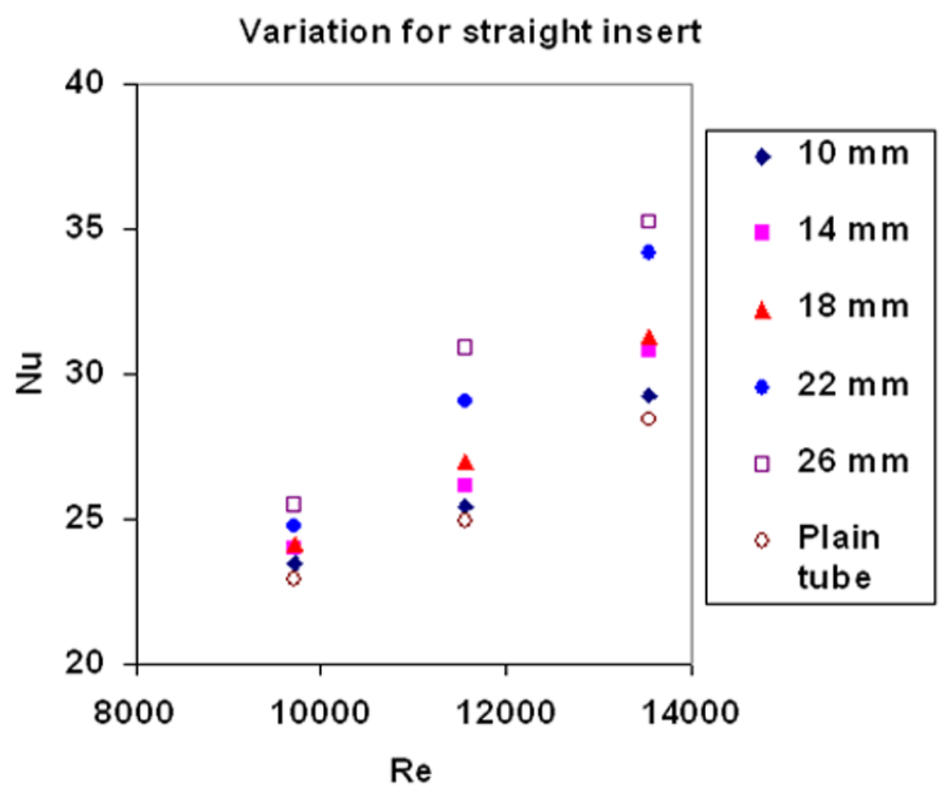

Figure 5. Variation in Nusselt number with Reynolds number for straight tape inserts

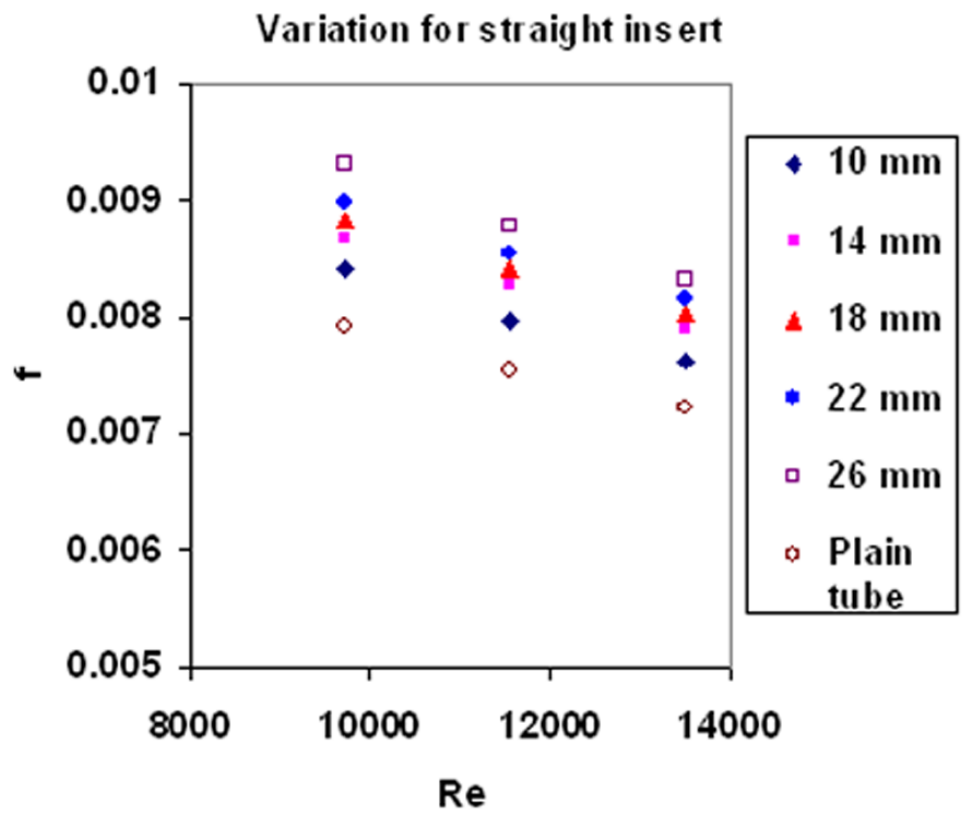

Figure 6. Variation in friction factor with Reynolds number for straight inserts 
The variations in friction factor with Reynolds number for the straight tape inserts are presented in Figure 6. It is observed that the friction factor gradually reduced with an increase in Reynolds number. It is observed to be maximum for the full-width straight tape insert. It is evident from Figure 7 that when a twisted tape is inserted into a plain tube there is a significant improvement in the Nusselt number due to secondary flow, with a greater enhancement being realized at higher Reynolds numbers and lower twist ratios. This enhancement is mainly due to the centrifugal forces resulting from the spiral motion of the fluid, and partly due to the tape acting as a fin. It is observed that a reduction in tape width causes a reduction in Nusselt number, as well as a reduction in the pressure drop. From Figure 7(a), the percentage increase in Nusselt numbers for the reduced-width tapes compared to plain tube are about $11-22 \%, 16-31 \%, 24-34 \%$ and $39-44 \%$ for tape widths of $10,14,18$ and $22 \mathrm{~mm}$ respectively and for a twist ratio $=3$. For full-width tapes, the percentage increase is observed to be 58 to $70 \%$ compared to the plain tube.

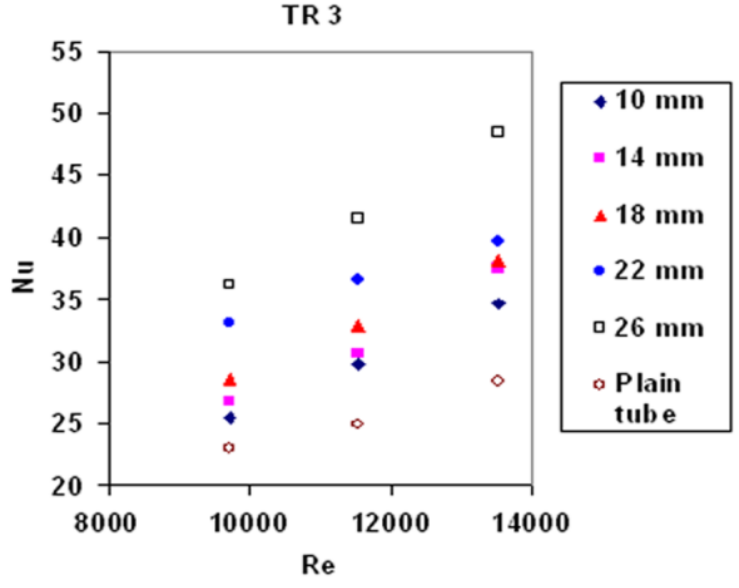

(a) Twist ratio $=3$

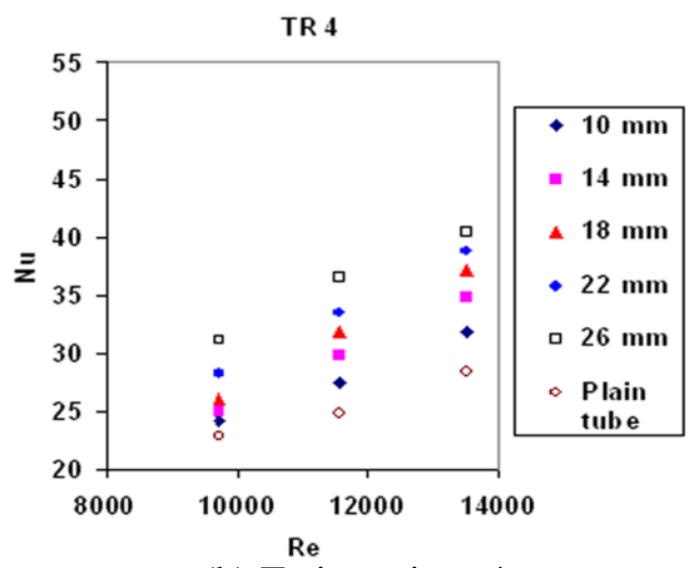

(b) Twist ratio $=4$

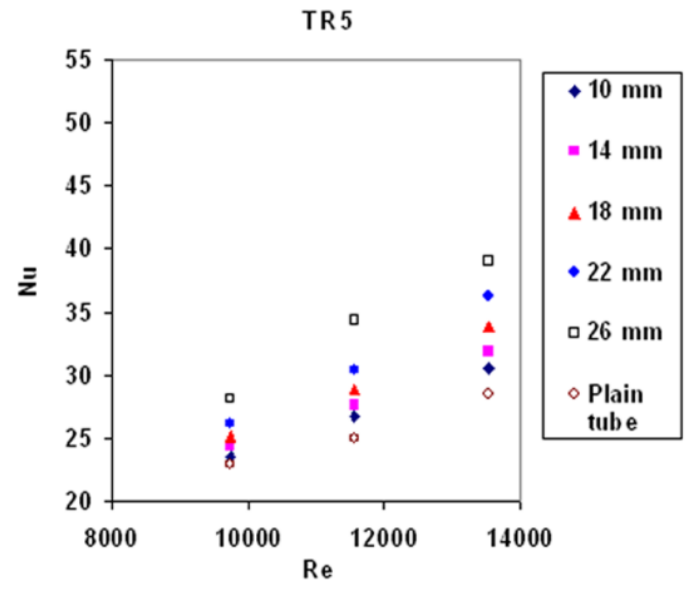

(c) Twist ratio $=5$

Figure 7. Variation in Nusselt number with Reynolds number

From Figure 7(b), the percentage increase in Nusselt numbers for reduced-width tapes compared to plain tube are about 5-12\%, 9-22\%, 13-30\% and 23-36\% for tape widths of $10,14,18$ and $22 \mathrm{~mm}$ respectively and for a twist ratio $=4$. For full-width 
tapes, the percentage increase is observed to be 36 to $42 \%$ compared to the plain tube. From Figure 7(c), the percentage increase in Nusselt numbers for reduced-width tapes compared to plain tube are about 2-8\%, 6-12\%, 9-19\% and 14-27\% for tape widths of $10,14,18$ and $22 \mathrm{~mm}$ respectively and for a twist ratio $=5$. For full-width tapes, the percentage increase is observed to be 22 to $37 \%$ compared to the plain tube.

The overall enhancement ratio is useful to evaluate the quality of heat transfer enhancement obtained over the plain tube at a constant pumping power. It is found to be more than unity for all the tape inserts used. Variations in the overall enhancement ratio $\eta$ against Reynolds number for twist ratios 3, 4 and 5 are shown in Figure 8. It is observed that overall enhancement ratio tended to decrease gradually with the rise in Reynolds number for all twist ratios. The maximum value of the overall enhancement ratio is 1.62 for a full-width twisted tape insert with a twist ratio equal to 3 .

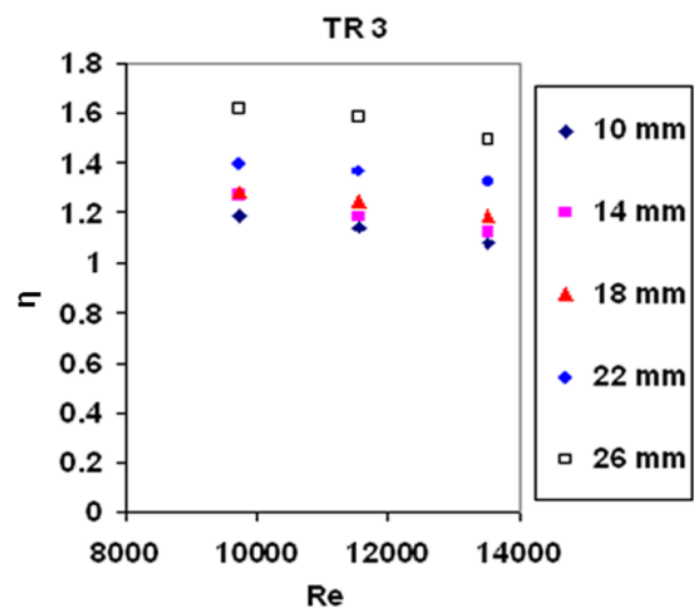

(a) Twist ratio $=3$

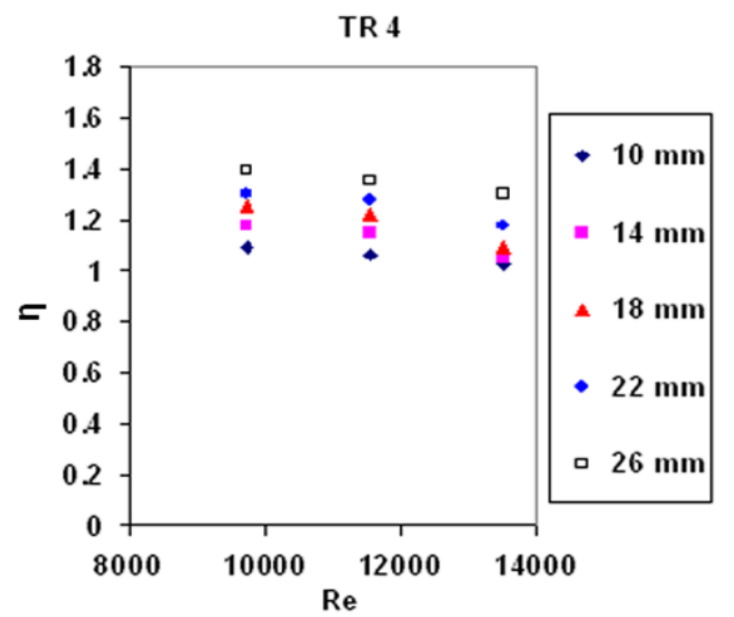

(b) Twist ratio $=4$

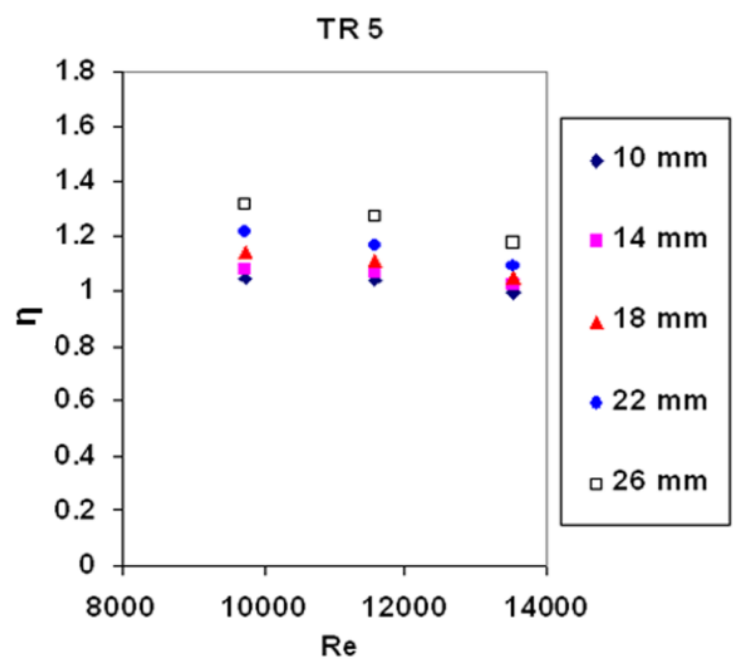

(c) Twist ratio $=5$

Figure 8. Variation in overall enhancement with Reynolds number

As seen in Figure 8(a), for tapes of widths of 26, 22, 18, 14 and $10 \mathrm{~mm}$ the curves are of decreasing order $(\eta=1.0-2.0)$ for pitches of $82.5,110$ and $137.5 \mathrm{~mm}$ in the range of Reynolds numbers from 8000 to 14000 . Each curve seems to have a 
maximum at a particular Reynolds number, $\operatorname{Re}=9727.13$, and the $\operatorname{Re}$ at which the maximum occurs decreases with the decrease in tape width. Tapes of $22 \mathrm{~mm}$ in width perform more or less like full-width tapes, and appear to do so slightly better than those for a twist ratio equal to $3(82.5 \mathrm{~mm}$ pitch). Even the tapes of $10 \mathrm{~mm}$ width have a $\eta$ value of about 1.08-1.18 times the plain tube. The gradual reduction in these curves basically represents the same performance of reduced-width tapes as that of the fullwidth tape. Thus the same performance can be achieved using reduced-width tapes with 15-61\% material saving at a higher Reynolds number and/or lower twist ratios. For $61 \%$ material savings (tapes of $22 \mathrm{~mm}$ width), the performance is 1.32-1.39 times better than for a plain tube.

\section{Heat Transfer Correlations:}

The present experimental results of the Nusselt number and friction factor are correlated in terms of Reynolds number and modified twist ratio as follows:

$$
\mathrm{Nu}=0.4141 * 10^{-4} * \operatorname{Re}^{0.9591}\left[(0.001+\mathrm{H} / \mathrm{w})^{-0.04645}\right] *\left(\mathrm{D}_{\mathrm{h}} / \mathrm{L}\right)^{-1.411}
$$

Average deviation $=6.246 \%$ and standard deviation $=7.983 \%$

$$
\mathrm{f}=0.01391 * \mathrm{Re}^{-0.1374}\left[(0.001+\mathrm{H} / \mathrm{w})^{-0.003}\right] *\left(\mathrm{D}_{\mathrm{e}} / \mathrm{L}\right)^{-0.2097}
$$

Average deviation $=2.216 \%$ and standard deviation $=2.692 \%$

Eqs. 15 and 16 are applicable when $3.17<\mathrm{H} / \mathrm{w}<61,0.02<\mathrm{D}_{\mathrm{e}} / \mathrm{L}<0.03$ and $6000<\mathrm{Re}<$ 13500

When $\mathrm{D}_{\mathrm{h}}=\mathrm{D}$ and $\mathrm{H} / \mathrm{w}=0$; Eqs. 15 and 16 are also applicable to plain tubes.

\section{CONCLUSION}

The study presents an experimental investigation of the potential of reduced-width twisted tape inserts to enhance the rate of heat transfer in a horizontal circular tube with an inside diameter of $27.5 \mathrm{~mm}$ with air as the working fluid. The Reynolds number varied from 6000 to 13500 . The effects of parameters such as the modified twist ratio, Reynolds number on the heat transfer and overall enhancement ratio are studied. The following conclusions can be drawn:

i) The enhancement in heat transfer with twisted tape inserts compared to the plain tube varied from 36 to $48 \%$ for full-width and 33 to $39 \%$ for reduced-width 22 $\mathrm{mm}$ inserts.

ii) The maximum friction factor rise was about $18 \%$ for $26 \mathrm{~mm}$ and only $17.3 \%$ for the reduced-width inserts compared to the plain tube.

iii) The overall enhancement ratio of the tubes with full-width twisted tape inserts is 1.62 for full-width $26 \mathrm{~mm}$ tape, and 1.39 for reduced-width $22 \mathrm{~mm}$ twisted tape inserts. A $61 \%$ material saving could be obtained for the reduced-width $22 \mathrm{~mm}$ inserts and the performance is $1.32-1.39$ times that of the plain tube.

iv) Correlations for the heat transfer coefficient and friction factor are proposed based on the present experimental data. The agreement between the results 
obtained from the experiment and those obtained from the proposed correlations is reasonable.

Thus the same performance can be achieved using reduced-width tape with $15 \%$ material saving at higher Reynolds numbers and/or lower twist ratios. Even for the $61 \%$ material saving twisted tape (of width $10.0 \mathrm{~mm}$ ) the performance is 1.08-1.18 times better than that for a smooth tube. Thus, from considerations of enhanced heat transfer and savings in pumping power and in tape material cost, the reduced-width tape inserts are seen to be attractive for enhancing the turbulent flow heat transfer in a horizontal circular tube. Future work may be extended:

- to change the tape material from aluminum to copper

- to the application of compound enhancement techniques, i.e. the tape inserts can be coupled with coil wire inserts for better enhancement.

\section{ACKNOWLEDGEMENT}

The authors wish to thank the Department of Mechanical Engineering, JNT University, Hyderabad for providing the facilities (under College Funds) to carry out this work.

\section{REFERENCES}

Akhavan-Behabadi, M.A., Ravi Kumar, A., Mohammadpour and M. Jamali-Asthiani 2009. Effect of twisted tape insert on heat transfer and pressure drop in horizontal evaporators for the flow of R-134a. International Journal of Refrigeration, 32(5): 922-930.

Al-Fahed, S. and Chakroun, W. 1996. Effect of tube-tape clearance on heat transfer for fully developed turbulent flow in a horizontal isothermal tube. International Journal of Heat Fluid Flow, 17(2): 173-178.

Al-Fahed, S., Chamra, L.M. and Chakroun, W. 1998. Pressure drop and heat transfer comparison for both microfin tube and twisted-tape inserts in laminar flow. Experimental Thermal Fluid Science, 18(4): 323-333.

Bergles, A.E., Blumenkrantz, A.R. and Taborek, J. 1974. Performance evaluation criteria for enhanced heat transfer surfaces. Proceedings of the 5th International Heat Transfer Conference, Tokyo, 2: 239-243.

Chang, S.W., Jan, Y.J. and Liou, J.S. 2007. Turbulent heat transfer and pressure drop in tube fitted with serrated twisted tape. International Journal of Thermal Sciences, 46: 506-518.

Dasmahapatra J.K. and Raja Rao, M. 1991. Laminar flow heat transfer to generalized power law fluids inside circular tubes fitted with regularly spaced twisted tape elements for uniform wall temperature condition. In: Fundamentals of heat transfer in non-Newtonian fluids. New York, ASME, pp. 51-58.

Hsieh, S.S. and Huang, I.W. 2000. Heat transfer and pressure drop of laminar flow in horizontal tubes with/without longitudinal inserts. Journal of Heat Transfer, 122: 465-475.

Hsieh, S.S., Liu, M.H. and Tsai, H.H. 2003. Turbulent heat transfer and flow characteristic in a horizontal circular tube with strip-type inserts, Part-I: Fluid mechanics. International Journal of Heat and Mass Transfer, 46: 823-835.

Jaisankar, S., Radhakrishnan, T.K., Sheeba, K.N. and Suresh, S. 2008. Experimental studies on heat transfer and friction factor characteristics of Thermosyphon solar 
water heater system fitted with left-right twisted tapes. International Journal of Applied Engineering Research, 3(8): 1091-1103.

Monheit. M. 1987. Experimental evaluation of the convective characteristics of tubes with twisted tape inserts. In: Advances in Enhanced Heat Transfer. New York, AMSE, pp. 11-18.

Naphon, P. 2006. Heat transfer and pressure drop in the horizontal double pipes with and without twisted tape insert. International Communications in Heat and Mass Transfer, 33: 166-175.

Patil, A.G. 2000. Laminar flow heat transfer and pressure drop characteristics of powerlaw inside tubes with varying width twisted tape inserts. ASME Transactions, 122: 143-149.

Promvonge, P. and Eiamsa-ard, S. 2007. Heat transfer behaviors in a tube with combined conical-ring and twisted-tape insert. International Communications in Heat and Mass Transfer, 34: 849-859.

Saha, S.K and Mallick D.N. 2005. Heat transfer and pressure drop characteristics of laminar flow in rectangular and square plain ducts and ducts with twisted-tape inserts. Transactions of the ASME, Journal of Heat Transfer, 127: 966-977.

Sarma, P.K., Subramanyam, T., Kishore, P.S., Dharma Rao, V. and Kakac, S. 2003. Laminar convective heat transfer with twisted tape inserts in a tube. International Journal of Thermal Sciences, 42: 821-828.

\section{Nomenclature}

A convective heat transfer area $(\pi \mathrm{DL})\left(\mathrm{m}^{2}\right)$

$\mathrm{A}_{0} \quad$ area of orifice $\left(\mathrm{m}^{2}\right)$

$\mathrm{A}_{\mathrm{p}} \quad$ test section inner tube area $\left(\Pi / 4 \mathrm{D}^{2}\right)\left(\mathrm{m}^{2}\right)$

$\mathrm{C}_{\mathrm{p}} \quad$ specific heat of air $(\mathrm{J} / \mathrm{kg} \mathrm{K})$

d air discharge through test section $\left(\mathrm{m}^{3} / \mathrm{sec}\right)$

$\mathrm{D}_{\mathrm{h}} \quad$ hydraulic diameter $(4 \mathrm{~A} / \mathrm{P})(\mathrm{m})$

$\mathrm{D} \quad$ inner diameter of test section (m)

$\mathrm{H} \quad$ pitch $(\mathrm{mm})$

w width of tape insert (mm)

H/D twist ratio

$\mathrm{H} / \mathrm{w}$ modified twist ratio

$\mathrm{f}_{\text {the }}$ friction factor(theoretical) for plain tube

$\mathrm{f} \quad$ friction factor(experimental) for plain tube

$\mathrm{f}_{\mathrm{i}} \quad$ friction factor obtained using tape inserts

$\mathrm{h} \quad$ experimental convective heat transfer coefficient $\left(\mathrm{W} / \mathrm{m}^{2} \mathrm{~K}\right)$

$\mathrm{h}_{\mathrm{w}} \quad$ manometer level difference $(\mathrm{m})$

$\mathrm{h}_{\text {air }} \quad$ equivalent height of air column, $(\mathrm{m})$

$\mathrm{k}$ thermal conductivity $(\mathrm{W} / \mathrm{mK})$

$\mathrm{L} \quad$ length of test section, $(\mathrm{m})$

$\mathrm{m}^{\cdot} \quad$ mass flow rate of air $(\mathrm{kg} / \mathrm{sec})$

$\mathrm{Nu}_{\mathrm{i}} \quad$ Nusselt number(experimental) with tape insert $\left(\mathrm{hD}_{\mathrm{h}} / \mathrm{k}\right)$

$\mathrm{Nu} \quad$ Nusselt number(experimental) for plain tube

$\mathrm{Nu}_{\text {the }}$ Nusselt number for plain tube (theoretical)

Pr Prandtl number

$\mathrm{p} \quad$ pitch $(\mathrm{m})$

$\mathrm{P} \quad$ wetted perimeter $(\mathrm{m})$ 
$\Delta \mathrm{P} \quad$ pressure drop across the test section, $(\mathrm{Pa})$

Q total heat transferred to air $(\mathrm{Qc}+\mathrm{Qr})(\mathrm{W})$

$\mathrm{Q}_{\mathrm{c}} \quad$ heat transferred to air by convection (W)

$\mathrm{Q}_{\mathrm{r}} \quad$ heat transferred to air by radiation, (W)

Re Reynolds number ( $\rho$ u D/ $\mu$ )

T1, T6 air temperature at inlet and outlet $\left({ }^{\circ} \mathrm{C}\right)$

$\mathrm{T} 2, \mathrm{~T} 3, \mathrm{~T} 4, \mathrm{~T} 5$ tube wall temperature $\left({ }^{\circ} \mathrm{C}\right)$

$\mathrm{T}_{\mathrm{s}} \quad$ average surface temperature of the working fluid $\left({ }^{\circ} \mathrm{C}\right)$

$\mathrm{T}_{\mathrm{b}} \quad$ bulk temperature $\left({ }^{\circ} \mathrm{C}\right)$

$\mathrm{U} \quad$ air velocity through test section $(\mathrm{m} / \mathrm{sec})$

\section{Greek symbols}

$v \quad$ kinematic viscosity of air $\left(\mathrm{m}^{2} / \mathrm{sec}\right)$

$\varepsilon_{\mathrm{C}} \quad$ emissivity of copper

$\mu \quad$ dynamic viscosity $(\mathrm{kg} / \mathrm{m} \mathrm{s})$

$\eta \quad$ overall enhancement ratio

$\rho_{\mathrm{w}} \quad$ density of water $\left(\mathrm{kg} / \mathrm{m}^{3}\right)$

$\rho_{\mathrm{a}} \quad$ density of air $\left(\mathrm{kg} / \mathrm{m}^{3}\right)$ 